\title{
Sleep Disorders and Medical Conditions in Women
}

\author{
Barbara A. Phillips, M.D., MSPH, ${ }^{1}$ Nancy A. Collop, M.D., ${ }^{2}$ Christopher Drake, Ph.D., ${ }^{3}$ \\ Flavia Consens, M.D., ${ }^{4}$ Alexandros N. Vgontzas, M.D., Sc.D., ${ }^{5}$ and Terri E. Weaver, Ph.D., R.N. ${ }^{6}$
}

\begin{abstract}
Sleep disorders affect women differently than they affect men and may have different manifestations and prevalences. With regard to obstructive sleep apnea (OSA), variations in symptoms may cause misdiagnoses and delay of appropriate treatment. The prevalence of OSA appears to increase markedly after the time of menopause. Although OSA as defined by the numbers of apneas/hypopneas may be less severe in women, its consequences are similar and perhaps worse. Therapeutic issues related to gender should be factored into the management of OSA. The prevalence of insomnia is significantly greater in women than in men throughout most of the life span. The ratio of insomnia in women to men is approximately 1.4:1.0, but the difference is minimal before puberty and increases steadily with age. Although much of the higher prevalence of insomnia in women may be attributable to the hormonal or psychological changes associated with major life transitions, some of the gender differences may result from the higher prevalence of depression and pain in women. Insomnia's negative impact on quality of life is important to address in women, given the high relative prevalence of insomnia as well as the comorbid disorders in this population. Gender differences in etiology and symptom manifestation in narcolepsy remain understudied in humans. There is little available scientific information to evaluate the clinical significance and specific consequences of the diagnosis of narcolepsy in women. Restless legs syndrome (RLS) is characterized by an urge to move the legs or other limbs during periods of rest or inactivity and may affect as much as $10 \%$ of the population. This condition is more likely to afflict women than men, and its risk is increased by pregnancy. Although RLS is associated with impaired quality of life, highly effective treatment is available.
\end{abstract}

\section{Introduction}

T HE EFFECTS OF SLEEP LOSS and sleep disturbance on central nervous system (CNS) function and human behavior have long been recognized. However, the association of sleep loss and sleep disorders with physical health has received clinical and research attention only recently. Further, investigations of sleep disturbances and disorders specifically in women are scant. The aim of this review is to update the clinician about sleep apnea, sleep and metabolic disorders, insomnia, narcolepsy, and restless legs syndrome (RLS) in women. This paper is a summary of reviews on sleep disor- ders and medical conditions presented at the Women and Sleep Workshop, convened by the National Sleep Foundation and the Atlanta School of Sleep Medicine in Washington DC, March 5-6, 2007.

\section{Sleep Disordered Breathing and Metabolic Disorders Epidemiology}

Obstructive sleep apnea (OSA) has been historically described as a disease of men, with early clinical research showing the estimated male/female ratio for disease prevalence

\footnotetext{
${ }^{1}$ Division of Pulmonary, Critical Care and Sleep Medicine, Division of Internal Medicine, University of KY College of Medicine, Lexington, Kentucky.

${ }^{2}$ Division of Pulmonary, Critical Care and Sleep Medicine, Johns Hopkins University, Baltimore, Maryland.

${ }^{3}$ Henry Ford Hospital/Wayne State College of Medicine, Henry Ford Hospital Sleep Center, Detroit, Michigan.

${ }^{4}$ Department of Neurology, University of Michigan, Ann Arbor, Michigan.

${ }^{5}$ Department of Psychiatry, College of Medicine Penn State University, Hershey, Pennsylvania.

${ }^{6}$ Biobehavioral and Health Sciences Division, University of Pennsylvania School of Nursing, Philadelphia, Pennsylvania.
} 
to be $10: 1-60: 1{ }^{1}$ However, these prevalence estimates were based on clinical studies that often had a referral bias. Newer studies suggest the male/female prevalence ratios are much lower, probably in the range of 3:1-2:1. In addition, women with OSA may have different clinical presentations, therapeutic considerations, and prognoses than do their male counterparts.

\section{Diagnosis}

In examining the diagnostic testing for OSA, there are several characteristics that differ between the genders. Women with OSA are more likely to have partial obstructions (hypopneas) than complete obstructions (apneas), and the respiratory disturbances have shorter mean and maximum durations. $^{2}$ In addition, women are more likely to have the upper airway resistance syndrome (UARS), a milder form of OSA; less likely to have positional OSA; and generally have the same severity of OSA but at higher body mass indices (BMI) compared with men. ${ }^{2-6}$ Perhaps the most striking difference between men and women is that women are much more likely to have rapid eye movement (REM)-related OSA.6,7

\section{Presentation}

Several factors could contribute to the discrepancy between the gender ratio of OSA in the general population and the proportion of clinically diagnosed OSA. These include gender-related differences in frequency or atypical symptom reports, ${ }^{8-11}$ differences between self-report and spouse report, ${ }^{12}$ and failure of physicians to recognize sleep apnea in women. The last is of particular importance, as there is evidence of higher healthcare use in women with OSA prior to receiving the diagnosis. ${ }^{13}$ Women with sleep apnea are more likely than men to have insomnia complaints, less likely to have been witnessed to have apnea by their bed partner during sleep, and frequently have concomitant depression, hypothyroidism, restless legs, nightmares, palpitations, and hallucinations. ${ }^{8-10}$ Further, tools that are commonly used to assess sleep apnea symptoms perform differently when applied to men and women. For example, the Epworth Sleepiness Scale $^{14}$ is more likely to identify men with sleepiness than women. ${ }^{10,11}$ Because of these differences in symptoms and presentation, it is possible that women are underreferred and underdiagnosed because they do not have the classic symptoms of excessive sleepiness and snoring.

\section{Pathophysiology of gender differences}

The differences in anatomy and physiology of the upper airway and control of breathing may play a role in the gender-related differences of OSA. Neck soft tissue volume is greater in men than in women, ${ }^{15,16}$ and men have larger soft palates and upper tongue volume, with a longer pharynx. ${ }^{15,17}$ Furthermore, although men have a greater upper airway diameter during wakefulness, they have more narrowing of the oropharyngeal space in the supine position compared with women. ${ }^{16-19}$ The contribution of obesity as a known risk factor for OSA in and of itself does not differ between genders except that women with OSA are likely to be more obese but men exhibit greater upper body obesity, as measured by smaller hip circumferences and greater subscapular skinfold thickness. ${ }^{20}$ Men also have different re- sponses of ventilatory drive to oxygen and carbon dioxide, which appears to predispose them to greater ventilatory instability during sleep.

Multiple hormonal influences affect the presentation and consequences of sleep-disordered breathing in women. Estrogen and progesterone have been implicated in the gender differences in OSA. In one study, women with OSA had significantly lower levels of 17-hydroxyprogesterone, progesterone, and estradiol than those without OSA. ${ }^{21}$ Testosterone seems to precipitate or worsen OSA. Exogenous administration of testosterone hormone for treatment of hypogonadism in men has been associated with an increase in the apnea-hypopnea index (AHI), and exogenous testosterone administration to 1 woman was reported to precipitate clinically significant OSA. ${ }^{22,23}$

Women with polycystic ovarian syndrome (PCOS), which is characterized by ovarian failure, obesity, and androgen excess, appear to be at higher risk for OSA than are healthy women controls. ${ }^{24}$ The relationship between sleep apnea and PCOS is a complicated one. Many studies, primarily in men, have shown that sleep apnea is associated with elevation of proinflammatory cytokines, insulin resistance, and visceral adipocity. ${ }^{25-31}$ These associations have not been studied in women with sleep apnea. However, the link between sleep apnea and insulin resistance led investigators to study the presence of sleep apnea in disorders in which insulin resistance is the primary pathogenetic mechanism. Several recent studies have established a strong link among PCOS, sleep apnea, and excessive daytime sleepines. ${ }^{24,31,32}$ Further, proinflammatory cyto-kines are elevated in women with PCOS, independent of obesity and sleep apnea, and are strongly connected with insulin resistance, providing further support for the hypothesized role of cytokines in sleep apnea, sleepiness, and cardiovascular morbidity. ${ }^{33,34}$ Interestingly, the use of cytokine neutralizing antibodies and regular exercise, possibly by improving insulin sensitivity, are beneficial in patients with sleep apnea. ${ }^{35,36}$

Menopause is associated with cessation of ovarian endocrine function, causing a reduction in endogenous estrogen and progesterone levels. The prevalence and clinical severity of OSA in women increase dramatically after menopause, with postmenopausal women having nearly double the rate of OSA as that observed in premenopausal women, even when accounting for neck circumference and BMI. ${ }^{37,38}$ The reasons for this appear to be multifactorial, perhaps related to changes in body habitus and overall fat distribution and differences in airway function related to hormonal changes. ${ }^{39,40}$

A cardinal symptom of OSA in men is sleepiness, and this symptom appears to be much less specific in women than in men. ${ }^{8-11}$ Excessive daytime sleepiness (EDS) affects $10 \%-$ $20 \%$ of the general population, and major risk factors include depression and obesity, conditions that are more prevalent in women. ${ }^{41,42}$ In a study of 5508 Swedish women, depression and anxiety were the most important predictors of EDS. ${ }^{43}$ Also, physical inactivity is independently associated with EDS and fatigue in the general population, ${ }^{43,44}$ as well as in patients with sleep apnea. ${ }^{45}$

\section{Treatment}

Continuous positive airway pressure (CPAP). Treatment of OSA should not be different for women than for men, but 
there are some nuances of treatment between genders that are worth mentioning. Nasal CPAP is the therapy of choice for OSA. The effectiveness of CPAP therapy depends heavily on consistent use. Only about half of those with sleep apnea use their CPAP nightly, and the decision to adhere to CPAP therapy is made early in the treatment period, typically during the first week. ${ }^{46}$ Thus, adherence to CPAP therapy is a significant challenge for clinicians.

The optimal nightly duration of CPAP use to restore normal functioning depends on the outcome of interest. For example, the greatest proportion of individuals with subjective sleepiness will have normal values for subjective sleepiness with average use of 4 hours per night, but improvement in objective sleepiness to normal levels requires 6 hours. ${ }^{47} \mathrm{~A}$ limited body of research examining gender differences in CPAP treatment adherence provides some support for gender-based differences in adherence, although findings are not consistent. One study of older sleep apnea patients found that female gender was predictive of better CPAP use, ${ }^{48}$ whereas another showed that female CPAP use was on average significantly less than that of male participants. ${ }^{49}$

A study on the determinants of long-term CPAP use found that women were more likely to initially refuse CPAP treatment and to later abandon its use. ${ }^{50}$ In sum, results of studies to determine the role of gender in predicting adherence to CPAP are conflicting, with men more likely to be adherent in some and women in others. ${ }^{48-51}$ In addition to the inconsistent data on CPAP adherence, gender differences in the response to CPAP treatment are virtually unknown.

In the general population, improvements in functional status as well as such symptoms as daytime sleepiness and mood disturbances have been documented. ${ }^{52,53}$ Most of the research has been conducted in predominantly male samples with severe OSA, however, and has failed to examine gender-specific results. Consequently, it remains unclear whether women's responses to treatment are similar to those of men. Small sample sizes and high male/female ratio seen in the clinical trials, especially in those only including patients with severe OSA, might prohibit meaningful genderbased comparisons in CPAP treatment response.

A final challenge with regard to CPAP treatment for women is their increased likelihood of milder disease; previous criteria for Medicare reimbursement for CPAP treatment were viewed as an unintended bias facing women with OSA. ${ }^{54}$ For example, an AHI of 30 was required for CPAP Medicare reimbursement. Most female patients might have a milder disease, with an AHI of 5-30, which was reflected by the observed increase in male/female ratio from 2:1 for mild OSA to 7:1 for severe OSA in a large retrospective study. ${ }^{6}$ Therefore, a large number of women with milder OSA would have been denied treatment. Fortunately, the new Medicare guidelines for reimbursement published in 2002 are more liberal and, therefore, might lessen this unintended gender bias. ${ }^{55}$

Mandibular advancement devices. The use of dental/oral appliances (OA), a second-line treatment for OSA, has also been examined regarding success between genders. In one large prospective study, women with OSA were more likely to have treatment success with OA than men, particularly those with milder forms of OSA. ${ }^{56}$ Men with OSA treated with OA were more likely to have treatment success when they had predominantly supine-dependent OSA and were more likely to develop treatment failure with even small changes in their BMI. ${ }^{57,58}$

Upper airway surgery. There are sparse data about potential gender differences in the outcome of upper airway surgery for the treatment of OSA, but one report suggests no gender-related differences in the use or side effects of mandibular advancement devices. ${ }^{59}$

Weight loss. Weight loss is an important treatment strategy for OSA; however, in one large community-based study, weight loss was found to be a more effective treatment strategy in men than in women. ${ }^{60}$

Hormone replacement therapy (HRT). Finally, because of the sharp upswing in OSA prevalence at menopause, it is reasonable to consider the effects of HRT on sleep-disordered breathing (SDB). Three large, well-done cohort studies demonstrated a reduced risk for sleep apnea in postmenopausal women who are taking HRT. ${ }^{37,61,62}$ In the Sleep Heart Health Study, ${ }^{61}$ women who were on HRT were less likely to have sleep apnea than those who were not, but overall lifestyle and healthcare are significant confounders in drawing conclusions about the efficacy of HRT for OSA. There are a few small interventional studies of HRT in SDB, but data are conflicting and limited. ${ }^{63}$ This discrepancy between observational and treatment studies will need to be clarified before firm recommendations can be made. Estrogen is an option to consider, but it would need to be discussed carefully with the patient because of recently recognized complications of HRT. Thus, management of sleep apnea in women is challenging. In one study, however, women with OSA had increased cardiovascular mortality compared with men; thus, although OSA is more common in men than women, the prevalence and impact of the disease are certainly not insignificant in women. ${ }^{64}$

\section{Insomnia}

\section{Epidemiology}

Population-based studies have found that $30 \%$ or more of the general population complain of sleep disturbances. However, it is important to distinguish the disorder of insomnia from the experience of short-term sleep disturbance. Sleep disturbance is often a transient response to identifiable stimuli and may not be associated with daytime consequences. In contrast, insomnia is a disorder characterized by chronic and frequently reported difficulty with sleep induction or maintenance or nonrestorative sleep, lasting a minimum of 1 month and associated with significant impairment in social, occupational, or other areas of functioning. ${ }^{65}$ Insomnia is also associated with significant morbidity, including reduced quality of life, falls in the elderly, and increased absenteeism, and is a risk factor for the development of major depression. ${ }^{66-68}$ Importantly, women of all ages have a higher prevalence of both sleep disturbance and insomnia than do men. ${ }^{69}$

The prevalence of DSM-IV-based insomnia (as opposed to sleep disturbance) in the general population is estimated to be between $9 \%$ and $15 \%$. These epidemiological studies are based on data collected over virtually the entire life span. ${ }^{69}$ 
One consistent finding among this large body of literature is the higher rate of insomnia found in women. A recent metaanalysis combining data from more than 29 studies encompassing 1,265,015 individuals demonstrated that women are at $41 \%$ greater risk for developing insomnia than are men. ${ }^{70}$ Furthermore, the greater risk of insomnia in women increases with age. In elderly populations $(\geq 65)$, the risk almost doubles, to a $73 \%$ greater risk for insomnia in older women than in older men. This higher prevalence of insomnia in women probably does not emerge until puberty, suggesting a possible contribution of hormonal changes. ${ }^{71}$ This study also found that increased rates of insomnia are associated with maturation during puberty in girls only.

\section{Comorbid insomnia}

The recent National Institutes of Health (NIH) State of the Science Conference on insomnia highlighted the fact that insomnia is most often comorbid with other conditions. ${ }^{72}$ In a recent National Sleep Foundation (NSF) poll, the presence of greater numbers of comorbid conditions was associated with significantly reduced sleep quality. ${ }^{73}$ However, it is often difficult to determine the nature of this association between insomnia and the comorbidity or the direction of causality. Issues related to the assessment and treatment of insomnia in women are particularly important in this regard, as many of the common co-morbidities with insomnia also have a higher prevalence rate in women. ${ }^{74}$

The most common comorbid conditions with insomnia are psychiatric diseases. ${ }^{75}$ Among psychiatric conditions, major depression and dysthymia, disorders with a much higher prevalence in women, are the disorders most closely associated with insomnia. ${ }^{76}$ In fact, a primary symptom of depression is sleep disturbance. Even after successful treatment of depression, however, several refractory symptoms may remain. Interestingly, sleep disturbance is the single most common refractory symptom in successfully treated depressed patients, ${ }^{77}$ suggesting the possibility that in many cases, insomnia may be an independent comorbid condition rather than merely a secondary symptom of the depression. Indeed, there is evidence that insomnia is associated with an overall increase of ACTH and cortisol secretion, which suggests that insomnia may be a disorder of CNS hyperarousal. ${ }^{78}$ In fact, recent studies have shown that specific treatment of insomnia in depressed patients not only improves the sleep disturbance but also reduces depressive symptomatology. ${ }^{79}$ Thus, it is important to consider insomnia and its treatment as an important and independent aspect of the overall care of women with depression.

Other common comorbidities with insomnia that also have a higher prevalence in women are chronic pain disorders. In fact, numerous studies have shown a close link between pain and insomnia, including the 2003 NSF Sleep in America poll, which showed that individuals who report bodily pain are 1.89 (95\% C.I. 1.28-2.78), 2.68 (95\% C.I. 2.06-3.49), 1.88 (95\% C.I. $1.32-$ 2.66), and 2.11 (95\% C.I. 1.54-2.90) times more likely to report "difficulty falling asleep," "frequent awakenings," "waking too early," or "waking unrefreshed," respectively. ${ }^{73}$ Not only does pain impact sleep, but sleep loss can have a significant impact on pain. One recent laboratory-controlled study showed that reductions in total sleep time significantly increase pain sensitivity, even in healthy, disease-free individuals. ${ }^{80}$

\section{Treatment}

At present, there are very few data regarding potential differential treatment effects of insomnia in women. Nonetheless, there is a vast treatment literature demonstrating the effectiveness of both behavioral and pharmacological treatment approaches to insomnia in men and women. ${ }^{81}$ Research has shown that the FDA-approved GABAA receptor agonists including older benzodiazepines and newer medications, such as eszopiclone, zaleplon, zolpidem, zolpidem-CR, and the melatonin 1 and 2 receptor agonist ramelteon, are effective at reducing sleep onset latency in samples of primary insomniacs, including women. ${ }^{82}$ Beneficial effects on reducing wake after sleep onset are also observed with the medications that have intermediate half-lives. However, the risk for residual daytime impairment increases with longeracting compounds.

Given the high rate of comorbidity with insomnia, it is important to consider treatment effects in insomnia coexisting with specific medical and psychiatric conditions. Treatment studies of comorbidities with a higher prevalence in women, such as depression and pain, are particularly germane in the present context. Despite the lack of data on long-term efficacy in insomnia, sedating antidepressants continue to be widely used in the context of treating sleep disturbance in depression. Several controlled studies have shown improvement in the sleep of depressed patients with coexisting insomnia when treated with newer as well as older hypnotic medications in conjunction with standard antidepressant treatment. ${ }^{83}$ In one study, depression outcome was improved with cotherapy of a hypnotic and an antidepressant in comparison to antidepressant therapy alone. ${ }^{79}$ In another study of comorbid insomnia and rheumatoid arthritis, patients reported improvement in sleep and morning stiffness after treatment with the short-acting hypnotic triazolam. ${ }^{84}$ Eszopiclone has been shown to improve sleep and menopause-related symptoms in perimenopausal and early postmenopausal women with insomnia. ${ }^{85}$ Future studies are needed to confirm these studies that demonstrate the benefit of hypnotic medications on both sleep and nonsleep outcomes.

Controlled studies have demonstrated improved sleep with cognitive behavioral treatments of insomnia in both men and women. This treatment strategy typically includes sleep hygiene instructions, stimulus control, sleep restriction therapy, and relaxation techniques used in combination. ${ }^{81}$ Similar to pharmacological treatment, cognitive behavioral treatment of insomnia has been shown to improve sleep in insomnia comorbid with a number of medical and psychiatric conditions. ${ }^{72,81}$ The benefits of this type of treatment have been shown to produce sleep improvements over longterm ( $>6$ months) follow-up. Behavioral treatments of insomnia associated with pain have demonstrated significant improvements in sleep and may even impact the level of pain as well. ${ }^{86,87}$

\section{Narcolepsy}

Narcolepsy is a life-long neurological disorder characterized by EDS and abnormal REM sleep manifestations, including cataplexy, sleep paralysis, hypnagogic hallucinations, and sleep-onset REM periods. Nocturnal sleep is usually disturbed. The International Classification of Sleep 
Disorders (ICSD-2) ${ }^{88}$ differentiates three types of narcolepsy: with cataplexy, without cataplexy, and secondary narcolepsy (when the direct cause of narcolepsy is a coexisting medical disorder). This review focuses primarily on narcolepsy with cataplexy.

Cataplexy is the brief, sudden transient loss of muscle tone triggered by strong emotions. Consciousness is preserved. Whether there are gender differences in cataplexy remains controversial: it has been reported there are no gender differences in symptom severity ${ }^{89}$ but that women develop cataplexy at a younger age. ${ }^{90}$

\section{Epidemiology}

Narcolepsy with cataplexy affects $0.02 \%-0.18 \%$ of the United States and Western European population. ${ }^{79}$ Prevalence in the general population increases to $25-56$ per 100,000 when cataplexy is not a required symptom for diagnosis, and male predominance has been reported using this definition (relative risk 1.6:1). Silber et al. ${ }^{91}$ report a greater relative risk of narcolepsy with cataplexy in men compared with women (1.2:1).

\section{Pathogenesis}

The exact etiology of narcolepsy is unknown. The association with HLA DQB1*0602 is well established, suggesting both a genetic component and a possible autoimmune etiology for the disease. In an animal model of narcolepsy, female Doberman puppies have more severe cataplexy episodes than do male puppies, which may suggest that the pathophysiological process involved in the canine narcolepsy model may involve differential development in females and males. ${ }^{92}$ The loss of hypocretin/orexin is a consistent finding in subjects with this disorder. These neuropeptides are localized to a few neurons in the dorsolateral hypothalamus. These hypocretin/orexin neurons project widely throughout the brain and appear to stabilize vigilance states.

Daniels, ${ }^{93}$ in 1934 , noted that half of his narcoleptic patients gained a considerable amount of weight when diagnosed with this disorder, a finding that was more frequent in women. Mice lacking hypocretin/orexin peptide manifest symptoms of narcolepsy with cataplexy. Female mice lacking hypocretin/orexin are obese, but male mice are not; the reason for this difference is not known, but leptin levels are influenced by sex, hormones, and cytokines. Female rats have higher levels of preprohypocretin mRNA in the hypothalamus, and leptin affects its signaling. Elucidating the underlying mechanisms of gender differences in preprohypocretin may also contribute to our understanding of obesity. ${ }^{94}$

Tumor necrosis factor- $\alpha$ (TNF- $\alpha$ ) is elevated in some sleep disorders characterized by EDS, including narcolepsy. ${ }^{25}$ Himmerich et al. ${ }^{95}$ suggested that narcoleptic patients have a functional alteration in the TNF- $\alpha$ cytokine level, a difference mainly found in women. Okun et al. ${ }^{96}$ reported that narcoleptic subjects have higher serum levels of TNF- $\alpha$ and interleukin-6 (IL-6). Although no gender differences in these cytokines were reported, the possibility remains that cytokines may be involved in the development of narcolepsy. Gender differences may be an important consideration in the treatment of narcolepsy, although clinical studies address- ing pharmacogenetics are lacking. Dauvilliers et al. ${ }^{97}$ reported that the optimal dose of modafinil for narcoleptic women is approximately $100 \mathrm{mg}$ lower than that for men, probably because of the sexual dimorphism of the catecholO-methyltransferase (COMT) gene, which plays a crucial role in the metabolism of dopamine.

\section{Impact on quality of life}

Narcolepsy clearly has a negative effect on the quality of life, most profoundly affecting bodily pain, social function, and general health. Whether or not there are gender differences in symptom onset or severity in narcoleptic subjects, women express more social limitations as a result of this sleep disorder than do men. ${ }^{98}$

\section{Treatment}

The importance of sleep hygiene must be emphasized. Behavioral measures to enhance alertness during critical times of the day must be considered. Scheduled naps are often helpful. If medications are needed, these are directed toward symptomatic improvement. For the treatment of EDS, wakepromoting agents (such as modafinil) or stimulants (such as methylphenidate or dextroamphetamines) improve alertness in most narcoleptics. For treatment of cataplexy, serotonin reuptake inhibitors (SSRIs) and tricyclic antidepressants are effective. Gamma-hydroxybutyrate (GHB) treats more severe cataplexy and improves daytime sleepiness as well.

There are no controlled studies in humans regarding the safety of these medications during pregnancy. As the potential for teratogenicity is unknown, each case must be addressed individually to carefully evaluate the benefits of the treatment over potential risk to the fetus.

\section{Restless Legs Syndrome}

According to the International Classification of Sleep Disorders, ${ }^{99}$ the diagnosis of RLS in adults can be made when:

A. The patient reports an urge to move the legs, usually accompanied or caused by uncomfortable and unpleasant sensations in the legs.

B. The urge to move or the unpleasant sensations begin or worsen during periods of rest or inactivity, such as lying or sitting.

C. The urge to move or the unpleasant sensations are partially or totally relieved by movement, such as walking or stretching, or at least as long as the activity continues.

D. The urge to move or the unpleasant sensations are worse or only occur in the evening or night.

F. The condition is not better explained by another current sleep disorder, medical or neurological disorder, mental disorder, medication use, or substance use disorder.

\section{Epidemiology}

As many as $90 \%$ of people with RLS have periodic limb movements (PLMs) during sleep. ${ }^{100}$ The rate of PLMs correlates with subjective RLS severity, ${ }^{101}$ and PLMs that are associated with arousals are associated with disturbed sleep in older women. ${ }^{101}$ It is important to note, however, that PLMs are very common with many sleep disorders, including SDB. ${ }^{102}$ Periodic leg movements are not more prevalent in 
insomnia or hypersomnia but are specifically associated with sleep disorders involving dopaminergic impairment. ${ }^{103}$ They also increase with aging ${ }^{104}$ and are frequently seen in patients who are taking antidepressants. ${ }^{105}$ Thus, whereas the presence of PLMs supports the diagnosis of RLS, limb movements are neither necessary nor sufficient to make the diagnosis.

The prevalence of RLS symptoms is about $10 \%$ in most population-based surveys, and there are consistently higher rates of RLS symptoms in women than in men. ${ }^{106-109}$ The rate of RLS may be lower in Asian than in European populations, ${ }^{110}$ but the prevalence in African Americans is similar to that in Caucasians. ${ }^{111}$ Because the diagnosis of RLS is based on symptom report, prevalence rates vary with different criteria for frequency and severity. For example, in the Restless Legs Syndrome Prevalence and Impact (REST) study, RLS symptoms were endorsed by $7.2 \%$ of the survey population. However, symptoms occurring at least twice per week were reported by only $5 \%$ of the subjects and were moderately or severely distressing in only $2.7 \% .{ }^{112}$

\section{Pathophysiology}

RLS may be classified as primary or secondary. Primary or idiopathic RLS is more likely to develop at an earlier age, may have no known associated or predisposing factors, and appears to have a genetic basis. First-degree and second-degree relatives of patients with idiopathic RLS have a significantly increased risk of developing RLS compared with relatives of matched controls. ${ }^{112}$ RLS may also be secondary to a variety of medical conditions that have iron deficiency in common; these include iron-deficiency anemia, end-stage renal disease, and pregnancy. ${ }^{113}$

Pregnancy is an important risk factor for RLS, both during the pregnancy and in subsequent years. ${ }^{107,114,115}$ About a quarter of pregnant women experience RLS symptoms, especially in the third trimester. Symptoms typically resolve promptly with delivery. Lower hemoglobin, mean corpuscular volumes, and serum folate levels appear to be risk factors for RLS in pregnancy. ${ }^{114,115}$ In the years after pregnancy, the risk of RLS is associated with bearing children in a dosedependent way. In one study, nulliparous women had the same risk for RLS as did men up to age 64. However, for women who had borne children, the risk of RLS increased with the number of children. A woman with one child had twice the risk of RLS as a nulliparous woman, and the risk increased with additional children. ${ }^{107}$

Understanding of the pathophysiology of RLS is currently an active area of research, and dysfunction of both iron and dopamine have been implicated. ${ }^{116}$

\section{Impact on quality of life}

Quality of life in patients with RLS is reduced to a degree equivalent to the reduction seen in patients with other chronic diseases. ${ }^{108}$ Adults with symptoms of RLS may be at increased risk for sleep apnea, insomnia, drowsy driving, being late to work, missing work, and making errors at work. ${ }^{117}$ RLS is also associated with anxiety and depression. ${ }^{118}$

\section{Treatment}

The treatment of RLS includes both behavioral and pharmacological approaches. Exercise in moderation may be ben- eficial. ${ }^{119}$ Folic acid has been reported to improve symptoms in pregnant patients with RLS who are folate deficient. ${ }^{120}$ Iron replacement appears to reduce or eliminate symptoms in patients who have serum ferritin levels $<45 \mu \mathrm{g} / \mathrm{L} .^{121}$ There are many anecdotal reports of relief with moderate exercise, massage, caffeine and alcohol avoidance, vitamins, and hot baths. Patients may benefit from being empowered to try these approaches.

Dopaminergic therapy is clearly first-line pharmacological treatment and is very effective in improving or eliminating symptoms. ${ }^{122}$ Two medications, ropinirole and pramipexole are FDA approved for the treatment or RLS, but they are not safe for use in pregnant or nursing women.

\section{Conclusions}

Women are more likely to have sleep complaints than are men for several reasons, including hormonal changes throughout the life span, the increased likelihood of an atypical presentation of OSA, a higher prevalence of depression, and increased likelihood of RLS. As most sleep disorders are treatable, increased awareness of the presentation and impact of sleep disorders in women can improve health and quality of life outcomes for these patients. Future investigation of the differences between men and women in the impact and treatment effects of sleep disorders is urgently needed.

\section{Disclosure Statement}

No competing financial interests exist.

\section{References}

1. Chaudhary BA, Speir WA Jr. Sleep apnea syndromes. South Med J 1982;75:39.

2. Leech JA, Onal E, Dulberg C, Lopata M. A comparison of men and women with occlusive sleep apnea syndrome. Chest 1988;94:983.

3. Exar EN, Collop NA. The upper airway resistance syndrome. Chest 1999;115:1127.

4. Guilleminault C, Quera-Salva MA, Partinen M, Jamieson A. Women and the obstructive sleep apnea syndrome. Chest 1988;93:104.

5. Redline S, Kump K, Tishler PV, Browner I, Ferrette V. Gender differences in sleep disordered breathing in a community-based sample. Am J Respir Crit Care Med 1994; 149:722.

6. O'Connor C, Thornley KS, Hanly PJ. Gender differences in the polysomnographic features of obstructive sleep apnea. Am J Respir Crit Care Med 2000;161:1465.

7. Ware JC, McBrayer RH, Scott JA. Influence of sex and age on duration and frequency of sleep apnea events. Sleep 2000;23:165.

8. Valipour A, Lothaller H, Rauscher H, Zwick H, Burghuber OC, Lavie P. Gender -related differences in symptoms of patients with suspected breathing disorders in sleep: A clinical population study using the Sleep Disorders Questionnaire. Sleep 2007;30:312.

9. Shepertycky MR, Banno K, Kryger MH. Differences between men and women in the clinical presentation of patients diagnosed with obstructive sleep apnea syndrome. Sleep 2005;28:309.

10. Baldwin CM, Kapur VK, Holberg CJ, Rosen C, Nieto FJ, and the Sleep Heart Health Study Group. Associations between gender and measures of daytime somnolence in the Sleep Heart Health Study. Sleep 2004;27:305. 
11. Chervin RD, Aldrich MS. The Epworth Sleepiness Scale may not reflect objective measures of sleepiness or sleep apnea. Neurology 1999;52:125.

12. Wiggins CL, Schmidt-Nowara WW, Coultas DB, Samet JM. Comparison of self- and spouse reports of snoring and other symptoms associated with sleep apnea syndrome. Sleep 1990;13:245.

13. Smith R, Ronald J, Delaive K, Walld R, Manfreda J, Kryger $\mathrm{MH}$. What are obstructive sleep apnea patients being treated for prior to this diagnosis? Chest 2002;121:164.

14. Johns MW. Daytime sleepiness, snoring, and obstructive sleep apnea. The Epworth Sleepiness Scale. Chest 1993;103:30.

15. Whittle AT, Marshall I, Mortimore IL, Wraith PK, Stellar RJ, Douglas NJ. Neck soft tissue and fat distribution: Comparison between normal men and women by magnetic resonance imaging. Thorax 1999;54:323.

16. Pillar G, Malhotra A, Fogel R, Beauregard J, Schnall R, White DP. Airway mechanics and ventilation in response to resistive loading during sleep: Influence of gender. Am J Respir Crit Care Med 2000;162:1627.

17. Brooks LJ, Strohl KP. Size and mechanical properties of the pharynx in healthy men and women. Am Rev Respir Dis 1992;146:1394.

18. Mohsenin V. Gender differences in the expression of sleepdisordered breathing: Role of upper airway dimensions. Chest 2001;120:1442.

19. Martin SE, Mathur R, Marshall I, Douglas NJ. The effect of age, sex, obesity and posture on upper airway size. Eur Respir J 1997;10:2087.

20. Millman RP, Carlisle CC, McGarvey ST, Eveloff Se, Levinson PD. Body fat distribution and sleep apnea severity in women. Chest 1995;107:362.

21. Netzer NC, Eliasson AH, Strohl KP. Women with sleep apnea have lower levels of sex hormones. Sleep Breath 2003;7:25.

22. Schneider BK, Pickett CK, Zwillich CW, et al. Influence of testosterone on breathing during sleep. I Appl Physiol 1986;61:618.

23. Johnson MW, Anch AM, Remmers JE. Induction of the obstructive sleep apnea syndrome in a woman by exogenous androgen administration. Am Rev Respir Dis 1984;129:1023.

24. Fogel RB, Malhotra A, Pillar G, Pittman SD, Dunaif A, White DP. Increased prevalence of obstructive sleep apnea syndrome in obese women with polycystic ovary syndrome. J Clin Endocrinol Metab 2001;86:1175.

25. Vgontzas AN, Papanicolaou DA, Bixler EO, Kales A, Tyson K, Chrousos GP. Elevation of plasma cytokines in disorders of excessive daytime sleepiness: Role of sleep disturbance and obesity. J Clin Endocrinol Metab 1997; 82:1313.

26. Vgontzas AN, Papanicolaou DA, Bixler EO, et al. Sleep apnea and daytime sleepiness and fatigue: Relation to visceral obesity, insulin resistance, and hypercytokinemia. J Clin Endocrinol Metab 2000;85:1151.

27. Punjabi NM, Sorkin JD, Katzel LI, Goldberg A, Schwartz A, Smith PL. Sleep-disordered breathing and insulin resistance in middle-aged and overweight men. Am J Respir Crit Care Med 2002;165:677.

28. Ip MS, Lam B, Ng MM, Lam WK, Tsang KW, Lam KS. Obstructive sleep apnea is independently associated with insulin resistance. Am J Respir Crit Care Med 2002;165:670.

29. Harsch I, Schahin S, Radespiel-Troger M, et al. Continuous positive airway pressure treatment rapidly improves insulin sensitivity in patients with obstructive sleep apnea syndrome. Am J Respir Crit Care Med 2004; 169:156.
30. Mehra R, Storfer-Isser A, Kirchner L, et al. Soluble interleukin 6 receptor. A novel marker of moderate to severe sleep-related breathing disorder. Arch Intern Med 2006; 166:1725.

31. Vgontzas AN, Legro RS, Bixler EO, Grayev A, Kales A, Chrousos GP. Polycystic ovary syndrome is associated with obstructive sleep apnea and daytime sleepiness: Role of insulin resistance. J Clin Endocrinol Metab 2001;86:517.

32. Tasali E, Van Cauter E, Ehrmann AD. Relationships between sleep disordered breathing and glucose metabolism in polycystic ovary syndrome. J Clin Endocrinol Metab 2006;91:36.

33. Vgontzas AN, Bixler EO, Chrousos GP. Sleep apnea is a manifestation of the metabolic syndrome. Sleep Med Rev 2005;9:211.

34. Vgontzas AN, Trakada G, Bixler EO, et al. Plasma interleukin 6 levels are elevated in polycystic ovary syndrome independently of obesity or sleep apnea. Metabolism 2006; 55:1076.

35. Vgontzas AN, Zoumakis E, Lin H-M, Vela-Bueno A, Chrousos P. Marked decrease of sleepiness in patients with sleep apnea by etanercept. J Clin Endocrinol Metab 2004;89:4409.

36. Peppard PE, Youing T. Exercise and sleep-disordered breathing: An association independent of body habitus. Sleep 2004;27:480.

37. Bixler EO, Vgontzas AN, Lin HM, et al. Prevalence of sleepdisordered breathing in women: Effects of gender. Am J Respir Crit Care Med 2001;163:608.

38. Dancey DR, Hanly PJ, Soong C, Lee B, Hoffstein V. Impact of menopause on the prevalence and severity of sleep apnea. Chest 2001;120:151.

39. Popovic RM, White DP. Upper airway muscle activity in normal women: Influence of hormonal status. J Appl Physiol 1998;84:1055.

40. Resta O, Bonfitto P, Sabato R, De Pergola G, Barbar MP. Prevalence of obstructive sleep apnoea in a sample of obese women: Effect of menopause. Diabetes Nutr Metab 2004; 17:296.

41. Bixler EO, Vgontzas AN, Lin HM, Calhoun SL, Vela-Bueno A, Kales A. Excessive daytime sleepiness in a general population sample: The role of sleep apnea, age, obesity, diabetes, and depression. J Clin Endocrinol Metab 2005;90:4510.

42. Vgontzas AN, Bixler EO, Tan T-L, Kantner D, Martin LE, Kales A. Obesity without sleep apnea is associated with daytime sleepiness. Arch Intern Med 1998;158:1333.

43. Theorell-Haglöw J, Lindberg E, Janson C. What are the important risk factors for daytime sleepiness and fatigue in women? Sleep 2006;29:751.

44. Resnick H, Carter E, Aloia M, Phillips B. Cross-sectional relationship of reported fatigue to obesity, diet, and physical activity: Results from the Third National Health and Nutrition Examination Survey. J Clin Sleep Med 2006;2:163.

45. Basta M, Lin H, Pejovic S,Sarrigiannidis A, Bixler EO, Vgontzas AN. Lack of regular exercise, depression, and degree of apnea are predictors of excessive daytime sleepiness in patients with sleep apnea: Sex differences. J Clin Sleep Med 2008;4:19-25.

46. Weaver TE. Adherence to positive airway pressure therapy. Curr Opin Pulm Med 2006;12:409.

47. Weaver T, Maislin G, Dinges D, et al. Relationship between hours of CPAP use and achieving normal levels of sleepiness and daily functioning. Sleep 2007;30:711.

48. Pelletier-Fleury N, Rakotonanahary D, Fleury B. The age and other factors in the evaluation of compliance with nasal 
continuous positive airway pressure for obstructive sleep apnea syndrome. A Cox's proportional hazard analysis. Sleep Med 2001;2:225.

49. Lewis KE, Seale L, Bartle IE, Watkins AJ, Ebden P. Early predictors of CPAP use for the treatment of obstructive sleep apnea. Sleep 2004;27:134.

50. McArdle N, Devereux G, Heidarnejad H, Englemann HM, Mackay TW, Douglas NJ. Long-term use of CPAP therapy for sleep apnea/hypopnea syndrome. Am J Respir Crit Care Med 1999;159:1108.

51. Sin DD, Mayers I, Man GC, Pawluk L. Long-term compliance rates to continuous positive airway pressure in obstructive sleep apnea: A population-based study. Chest 2002;121:430.

52. Giles TL, Lasserson TJ, Smith BH, White J, Wright J, Cates CJ. Continuous positive airways pressure for obstructive sleep apnoea in adults. Cochrane Database Syst Rev 2006;3:CD001106.

53. Gay P, Weaver T, Loube D, Iber C. Evaluation of positive airway pressure treatment for sleep-related breathing disorders in adults. Sleep 2006;29:381.

54. Kapsimalis F, Kryger MH. Gender and obstructive sleep apnea syndrome, part 1: Clinical features. Sleep 2002; 25:412.

55. Centers for Medicare and Medicaid Services. Available at www.cms.gov Accessed December 16, 2007.

56. Marklund M, Stenlund H, Franklin KA. Mandibular advancement devices in 630 men and women with obstructive sleep apnea and snoring: Tolerability and predictors of treatment success. Chest 2004;125:1270.

57. Schmidt-Nowara W, Lowe A, Wiegand L, Cartwright R, Perez-Guerra F, Menn S. Oral appliances for the treatment of snoring and obstructive sleep apnea: a review. Sleep 1995; 18:501.

58. Engleman HM, McDonald JP, Graham D, et al. Randomized crossover trial of two treatments for sleep apnea/hypopnea syndrome: Continuous positive airway pressure and mandibular repositioning splint. Am J Respir Crit Care Med 2002;166:855.

59. McGown AD, Makker HK, Battagel JM, L'Estrange PR, Grant HR, Spiro SG. Long-term use of mandibular advancement splints for snoring and obstructive sleep apnoea: A questionnaire survey. Eur Respir J 2001;17:462.

60. Newman AB, Foster G, Givelber R, Nieto FJ, Redline S, Young T. Progression and regression of sleep-disordered breathing with changes in weight: The Sleep Heart Health Study. Arch Intern Med 2005;165:2408.

61. Shahar E, Redline S, Young, et al., for the Sleep Heart Health Study. Hormone replacement therapy and sleepdisordered breathing. Am J Crit Care Med 2003;167: 1186.

62. Young T, Finn L, Austin D, Peterson A. Menopausal status and sleep-disordered breathing in the Wisconsin Sleep Cohort Study. Am J Respir Crit Care Med 2003;167:1181.

63. Polo-Kantola P, Rauhala E, Helenius H, Erkkola R, Irjala K, Polo O. Breathing during sleep in menopause: A randomized, controlled, crossover trial with estrogen therapy. $\mathrm{Ob}-$ stet Gynecol 2003;102:68.

64. Young T, Finn L. Epidemiological insights into the public health burden of sleep disordered breathing: Sex differences in survival among sleep clinic patients. Thorax 1998;53:S16.

65. American Psychiatric Association. Diagnostic and statistical manual of mental disorders, 4th ed. Washington, DC: American Psychiatric Association, 1994.
66. Katz DA, McHorney CA. The relationship between insomnia and health-related quality of life in patients with chronic illness. J Fam Pract 2002;51:229.

67. Leger D, Guilleminault C, Bader G, Levy E, Paillard M. Medical and socio-professional impact of insomnia. Sleep 2002;25:625.

68. Roth T, Ancoli-Israel S. Daytime consequences and correlates of insomnia in the United States: Results of the 1991 National Sleep Foundation Survey. II. Sleep 1999; 22:S354.

69. Ohayon MM. Epidemiology of insomnia: What we know and what we still need to learn. Sleep Med Rev 2002;6:97.

70. Zhang B, Wing YK. Sex differences in insomnia: A metaanalysis. Sleep 2006;29:85.

71. Johnson EO, Roth T, Schultz L, Breslau N. Epidemiology of DSM-IV insomnia in adolescence: Lifetime prevalence, chronicity, and an emergent gender difference. Pediatrics 2006;117:247.

72. NIH. National Institutes of Health State of the Science Conference Statement: Manifestations and management of chronic insomnia in adults. Sleep 2005;28:1049.

73. Foley D, Ancoli-Israel S, Britz P, Walsh J. Sleep disturbances and chronic disease in older adults: Results of the $2003 \mathrm{Na}$ tional Sleep Foundation Sleep in America Survey. I Psychosom Res 2004;56:497.

74. Moline ML, Broch L, Zak R. Sleep in women across the life cycle from adulthood through menopause. Med Clin North Am 2004;88:705.

75. Ford DE, Kamerow DB. Epidemiologic study of sleep disturbances and psychiatric disorders. An opportunity for prevention? JAMA 1989;262:1479.

76. Nowell PD, Buysse DJ, Reynolds CF 3rd, et al. Clinical factors contributing to the differential diagnosis of primary insomnia and insomnia related to mental disorders. Am J Psychiatry 1997;154:1412.

77. Nierenberg AA, Wright EC. Evolution of remission as the new standard in the treatment of depression. I Clin Psychiatry 1999;60:7.

78. Vgontzas AN, Bixler EO, Lin HM, et al. Chronic insomnia is associated with nyctohemeral activation of the hypothalamic-pituitary-adrenal axis: Clinical implications. I Clin Endocrinol Metab 2001;86:3787.

79. Fava M, McCall WV, Krystal A, et al. Eszopiclone co-administered with fluoxetine in patients with insomnia coexisting with major depressive disorder. Biol Psychiatry 2006;59:1052.

80. Roehrs T, Hyde M, Blaisdell B, Greenwald M, Roth T. Sleep loss and REM sleep loss are hyperalgesic. Sleep 2006;29:145.

81. Stepanski EJ, Rybarczyk B. Emerging research on the treatment and etiology of secondary or comorbid insomnia. Sleep Med Rev 2006;10:7.

82. Curry DT, Eisenstein RD, Walsh JK. Pharmacologic management of insomnia: Past, present, and future. Psychiatr Clin North Am 2006;29:871.

83. Jindal RD, Thase ME. Treatment of insomnia associated with clinical depression. Sleep Med Rev 2004;8:19.

84. Walsh JK, Muehlbach MJ, Lauter SA, Hilliker NA, Schweitzer PK. Effects of triazolam on sleep, daytime sleepiness, and morning stiffness in patients with rheumatoid arthritis. J Rheumatol 1996;23:245.

85. Soares CN, Joffe $H$, Rubens $R$, Caron J, Roth $T$, Cohen L. Eszopiclone in patients with insomnia during perimenopause and early postmenopause: A randomized controlled trial. Obstet Gynecol 2006;108: 1402 . 
86. Edinger JD, Wohlgemuth WK, Krystal AD, Rice JR. Behavioral insomnia therapy for fibromyalgia patients: A randomized clinical trial. Arch Intern Med 2005;165:2527.

87. Smith MT, Haythornthwaite JA. How do sleep disturbance and chronic pain inter-relate? Insights from the longitudinal and cognitive-behavioral clinical trials literature. Sleep Med Rev 2004;8:119.

88. American Academy Sleep Medicine. International Classification of Sleep Disorders, 2nd ed. West-chester, IL: American Academy of Sleep Medicine, 2005;79.

89. Guilleminault C. Narcolepsy. New York: Spectrum, 1976.

90. Honda Y. Clinical features of narcolepsy. Berlin: Springer Verlag, 1988.

91. Silber MH, Krahn LE, Olson EJ, Pankratz VS. The epidemiology of narcolepsy in Olmsted County, Minnesota: A population-based study. Sleep 2002;25:197.

92. Riehl J, Nishino S, Cederberg R, Dement WC, Mignot E. Development of cataplexy in genetically narcoleptic Dobermans. Exp Neurol 1998;152:292.

93. Daniels LE. Narcolepsy. Medicine 1934;13:1.

94. Fujiki N, Yoshida Y, Zhang S, Sakurai T, Yanagisawa M, Nishino S. Sex difference in body weight gain and leptin signaling in hypocretin/orexin deficient mouse models. Peptides 2006;27:2326.

95. Himmerich H, Beitinger PA, Fulda S, et al. Plasma levels of tumor necrosis factor alpha and soluble tumor necrosis factor receptors in patients with narcolepsy. Arch Intern Med 2006;166:1739.

96. Okun ML, Giese S, Lin L, Einen M, Mignot E, CoussonsRead ME. Exploring the cytokine and endocrine involvement in narcolepsy. Brain Behav Immun 2004;18:326.

97. Dauvilliers Y, Neidhart E, Billiard M, Tafti M. Sexual dimorphism of the catechol-O-methyltransferase gene in narcolepsy is associated with response to modafinil. Pharmacogenomics J 2002;2:65.

98. Ervik S, Abdelnoor M, Heier MS, Ramberg M, Strand G. Health-related quality of life in narcolepsy. Acta Neurol Scand 2006;114:198.

99. American Academy of Sleep Medicine. International Classification of Sleep Disorders, 2nd ed. Diagnostic and coding manual. Westchester, IL: American Academy of Sleep Medicine, 2005:180.

100. Garcia-Borreguero D, Larrosa O, de la Llave Y, Granizo JJ, Allen R. Correlation between rating scales and sleep laboratory measurements in restless legs syndrome. Sleep Med 2004;5:561.

101. Claman DM, Redline S, Blackwell T, et al. Prevalence and correlates of periodic limb movements in older women. J Clin Sleep Mod 2006;2:438.

102. Exar EN, Collop NA. The association of upper airway resistance with periodic limb movements. Sleep 2001;24:188.

103. Ancoli-Israel S, Kripke DF, Klauber MR, Mason WJ, Fell R, Kaplan O. Periodic limb movements in sleep in community-dwelling elderly. Sleep 1991;14:496.

104. Montplaisir J, Michaud M, Denesle R, Gosselin A. Periodic leg movements are not more prevalent in insomnia or hypersomnia but are specifically associated with sleep disorders involving a dopaminergic impairment. Sleep Med 2000;1:163.

105. Yang C, White DP, Winkelman JW. Antidepressants and periodic leg movements of sleep. Biol Psychiatry 2005;58:510.

106. Ulfberg J, Nystrom B, Carter N, Edling C. Restless legs syndrome among working-aged women. Eur Neurol 2001;46:17.
107. Berger K, Luedemann J, Trenkwalder C, John U, Kessler C. Sex and the risk of restless legs syndrome in the general population. Arch Intern Med 2004;164:196.

108. Allen RP, Walters AS, Montplaisir J, et al. Restless legs syndrome prevalence and impact: REST general population study. Arch Intern Med 2005;165:1286.

109. Phillips, BA, Young T, Finn L, Asher K, Hening WA, Purvis, C. Epidemiology of restless legs syndrome in adults. Arch Intern Med 2000;160:2137.

110. Tan EK, Seah A, See SJ, Lim E, Wong MC, Koh KK. Restless legs syndrome in an Asian population: A study in Singapore. Mov Disord 2001;16:577.

111. Lee HB, Hening WA, Allen RP, et al. Race and restless legs syndrome symptoms in an adult community sample in east Baltimore. Sleep Med 2007;7:642.

112. Winkelmann J, Wetter TC, Collado-Seidel V, et al.Clinical characteristics and frequency of the hereditary restless legs syndrome in a population of 300 patients. Sleep 2000;23:597.

113. Lesage $S$, Hening WA. The restless legs syndrome and periodic limb movement disorder: A review of management. Semin Neurol 2004;24:249.

114. Manconi M, Govoni V, De Vito A, et al. Restless legs syndrome and pregnancy. Neurology 2004;63:1065.

115. Lee KA, Zaffke ME, Baratte-Beebe K. Restless legs syndrome and sleep disturbance during pregnancy: The role of folate and iron. J Womens Health Gend Based Med 2001;10:335.

116. Montplaisir J, Allen RP, Walter, AS, Luigi Ferini-Strambi. Restless legs syndrome and periodic limb movements during sleep. In: Kryger MH, Roth T, Dement WC, eds. Principles and practice of sleep medicine, 4th ed. Philadelphia: Elsevier Saunders, 2005:839.

117. Phillips B, Hening W, Britz P, Mannino DM. Prevalence and correlates of restless legs syndrome: Results from the 2005 National Sleep Foundation poll. Chest 2006;129:76.

118. Picchietti D, Winkelman JW. Restless legs syndrome, periodic limb movements in sleep, and depression. Sleep 2005;28:891.

119. Aukerman MM, Aukerman D, Bayard M, Tudiver F, Thorp L, Bailey B. Exercise and restless legs syndrome: A randomized controlled trial. J Am Board Fam Med 2006;19:487.

120. Botez MI, Lambert B. Folate deficiency and restless-legs syndrome in pregnancy. N Engl J Med 1977;297:670.

121. Sun ER, Chen CA, Ho G, Earley CJ, Allen RP. Iron and the restless legs syndrome. Sleep 1998;21:371.

122. Hening WA, Allen RP, Earley CJ, Picchietti DL, Silber MH. An update on the dopaminergic treatment of restless legs syndrome and periodic limb movement disorder. Sleep 2004;27:560.

Address reprint requests to: Barbara A. Phillips, M.D., MSPH Division of Pulmonary, Critical Care and Sleep Medicine

Division of Internal Medicine University of KY College of Medicine 800 Rose Street Lexington, KY 40536-0298

E-mail: Rfphil1@uky.edu 
This article has been cited by:

1. Kathyryn A. Lee , Meir H. Kryger . 2008. Women and SleepWomen and Sleep. Journal of Women's Health 17:7, 1189-1190. [Abstract] [PDF] [PDF Plus] 